\title{
El tigre de Santa Julia, \\ la princesa italiana y \\ otras historias*
}

* Speckman G. Elisa, Del Tigre de Santa Fulia La princesa Italiana y otras historias, Sistema judicial, criminalidad y justicia en la ciudad de México (siglos XIX y XX), UNAM, Instituto de Investigaciones Históricas, Inacipe, 2014, 353 p.

Tla-MelauA, revista de Ciencias Sociales. Facultad de Derecho y Ciencias Sociales. Benemérita Universidad Autónoma de Puebla, México / IssN: 1870-6916 / Nueva Época, Año 8, No 37, octubre 2014 / marzo 2015, pp. 220-226. 
Aída Araceli Manzo Maldonado ${ }^{1}$

Elisa Speckman Guerra recorre de 1871 a 1921 los claroscuros de la justicia penal mexicana. Apunta que, para entender la real significación del derecho penal mexicano, se requiere considerar historias de estilos de vida orientados a observar diferencias de género, costumbres, ideología, la relatividad del delito en cuanto a lo permitido y lo prohibido, relacionado con los diferentes sectores socioeconómicos y culturales, enfatizando los privilegios que existían para las clases privilegiadas.

La primera parte es un recuento histórico. La frase "la independencia política se anticipó en años a la jurídica", de Jaime del Arenal, se refiere a la permanencia de los cuerpos hispanos durante las décadas que siguieron a la consumación de la Independencia. ${ }^{2}$ La sociedad de la Nueva España estaba compuesta por grupos heterogéneos con diferentes conjuntos normativos. En razón de ello, en el siglo XIx, los jueces tenían un amplio margen de decisión en el derecho escrito e incluso atendían las costumbres del lugar considerando las circunstancias particulares del caso.

La heterogeneidad de la población mexicana no impidió, al menos en su intencionalidad, que el modelo cívico que inspiró la independencia mexicana, sentara bases elementales para exigir a los juzgadores, imparcialidad, plena diferenciación de las partes, búsqueda de pruebas más allá de la confesional, así como la presencia de un abogado defensor. Todo ello definió las bases del sistema acusatorio.

La narrativa histórica es sugerente. Afirma que la Ley de Administración de Justicia, dictada en 1855 (conocida como Ley Juárez), es paradigmática: introduce cambios significativos; prohíbe que los tribunales eclesiásticos y militares procesen a civiles, ordena que los tribunales militares se ocupen exclusivamente de delitos cometidos por militares y establece que los delitos del fuero común cometidos por miembros del ejército sean competencia de los tribunales ordinarios. Hace notar, sin embargo, que a contra corriente de la Ley Juárez, los tribunales eclesiásticos siguieron hasta el final de este primer periodo de convivencia y sustitución, conociendo de los delitos comunes cometidos por los clérigos.

\footnotetext{
${ }^{1}$ Profesora investigadora en la Facultad de Derecho y Ciencias Sociales de la Benemérita universidad Autónoma de Puebla,(BUAP) (aida_araceli_m@hotmail.com)

${ }^{2}$ Del Arenal, "Ciencia jurídica española en el México del siglo XIX”, en La supervivencia del derecho español en Hispanoamérica durante la época independiente, p. 34. Para el tema de la permanencia de leyes e instituciones españolas pueden verse el resto de los capítulos que integran la obra citada.
} 
Con la aprobación del primer Código Penal y del Código Procesal Penal, el primero promulgado en 1871 y el segundo 9 años después, se concluyó la tarea de codificación en materia penal. Dichos ordenamientos ofrecieron a los jueces criterios de solución únicos y claros para asegurar la exacta aplicación de la ley. Los jueces solo debían buscar en el Código Penal la norma aplicable y en el procesal la forma de aplicarla. La justicia prometía unificarse y el libre arbitrio judicial había quedado reducido.

El texto recuerda la existencia del jurado popular, creado en 1869 y sin operar entre 1914 y 1919, integrado por un juez profesional cuyas sentencias se sustentaban en el veredicto votado por los miembros del jurado, compuesto por ciudadanos sin formación jurídica (el requisito para ser jurado era saber leer y escribir). Durante su existencia, no faltó quien descalificara la función de los jurados por su falta de conocimientos; además, afirmaban, concedían poca importancia a la vida, a la propiedad, tendían a simpatizar con los procesados y por ende, a absolverlos. Con ello, la institución no permitía conseguir el orden y la seguridad. Otros afirmaban que sus veredictos eran influidos por primeras impresiones, prejuicios o simpatías, la opinión pública y, sobre todo, el alegato de los abogados.

La segunda parte del libro muestra estampas de las mujeres criminales durante el Porfiriato. Sus fuentes son el expediente jurídico, los informes policiales y las notas periodistas. La revisión documental hace visible el estilo de vida de la mujer: su vida privada, familiar, amorosa y social en los diferentes sectores socioeconómicos y culturales. Circunstancias que mostraban discriminación, segregación y anulación y que, por lo general, no fueron consideradas por los juzgadores para entender las motivaciones que llevaron a las mujeres a delinquir. Por ejemplo, los casos de infanticidio son significativos: mujeres solas, trabajadoras, sin recursos ni lazos familiares.

El infanticidio era un recurso para ocultar el desliz y evitar ser señaladas y rechazadas tanto por la familia como por la sociedad; al no tener recursos para abortar, tenían al bebé y, al momento de nacer, lo mataban. Es interesante observar la diferencia entre la sentencia del infanticidio y la del homicidio. Los jueces asociaban el delito de infanticidio al ocultamiento de la deshonra; la clemencia tenía lugar. En cambio, el homicidio mereció una sanción más severa. El homicidio significó la transgresión femenina a su rol establecido por la sociedad.

Afirma que muchas de las conductas manejadas como delictivas eran en realidad transgresiones sociales, relacionadas con el comportamiento establecido para el género; es decir, significaba incumplimiento de las pautas que dictaba la sociedad. Es sugerente su explicación: quien no sigue el patrón cae en una "transgresión social" y se concibe como la "transgresión penal" a quien rompe las normas que establece el Código, haciendo una separación entre la conducta moral o religiosa y la legal. Sin embargo esto 
no se separa realmente; la mujer era sancionada con más pena porque al cometer un delito también había faltado a su comportamiento social. Es decir, un mismo delito merecía mayor pena en las mujeres. A mayor "transgresión social", mayor castigo a la "transgresión penal".

La separación entre clases sociales generaba una doble moral. A la mujer se le tenía muy restringida sobre todo en el aspecto sexual. Se le exigía un comportamiento diferente al hombre, debía ser virgen hasta el matrimonio, fiel y en caso de que enviudara tenía que permanecer casta hasta su muerte. La relatividad del delito es recurrente en el Porfiriato; la concepción de lo normal o anormal, lo permitido y lo prohibido y su aplicabilidad era relativa: altamente permisible para unos y totalmente punitiva para otros.

El régimen posrevolucionario no modificó sustancialmente al derecho penal mexicano. La historia de dos mujeres que mataron por despecho, y quizá por amor, sirven de ejemplo. Nydia Camargo (1925), quien mató a su amante —Alberto Márquez Briones, agregado comercial de la embajada de Chile—, fue absuelta por un jurado popular. Y Nydia Concetta di Leone (1936), quien mató a su marido — Vladirmir Nigeradze, príncipe ruso- fue condenada por tres jueces profesionales. Ambos casos son evidencia de cómo se manejaron por diferentes tribunales casos similares. En 1925 funcionaba el juicio por jurado y en 1936 ya se había suprimido; se crearon cortes penales, integradas por tres jueces profesionales: dos formas de entender y practicar la justicia conforme el sentir social y el impacto en la opinión pública.

El caso de Nydia rompe los valores socialmente aceptados (respeto al matrimonio, instinto maternal, resignación). En el juicio, el fiscal la señaló como una doble transgresora: adúltera y homicida; no se había divorciado de su marido que la maltrataba, al cual mostraba como una víctima, por el deshonor que le había hecho pasar; en segundo lugar, por matar a su amante que la explotaba. Los médicos que la evaluaron dictaminaron "estado de suma excitación que le impedía hablar"; argumentaron que fue víctima de un extranjero que denigraba a los mexicanos llamándoles: "ignorantes e incivilizados" y, en consecuencia, se defendió del "verdugo que tenía encadenados su corazón y voluntad", del derecho a no vivir como una esclava, del derecho a "vivir como una mujer amante y amada". Los miembros del tribunal le dieron la razón y la procesada fue absuelta.

Concetta, de origen italiano, se divorció para casarse con Vladimir y convertirse en princesa. Pero las cosas no funcionaron; ella perdió todo el dinero que había obtenido al divorciarse en el negocio de su nuevo esposo, el cual quebró por malos manejos. Él inició una relación extramarital, lo cual hizo que ella tuviera celos y lo siguiera para matarlo; posteriormente, intentó matarse pero alguien se lo impidió y fue enjuiciada. Su abogado argumentó enajenación mental y exceso de la defensa legítima del honor. 
Los jueces de la tercera corte penal aceptaron la petición del ministerio público de homicidio simple, y la sentenciaron a cumplir con ocho años de prisión. Su abogado apeló y la séptima sala del Tribunal de Justicia retomó el argumento de enajenación mental; sostuvo que había matado en un momento de locura impulsada por celos justificados. ${ }^{3}$ El abogado insistió en el exceso en la legítima defensa del honor y los magistrados revocaron la resolución de los jueces inferiores, considerando que el homicidio fue en exceso de defensa del honor, impusieron una pena de dos años de prisión. Salió en libertad condicional diez meses después de haber ingresado a prisión.

El caso de José de Jesús Negrete, mejor conocido como El Tigre de Santa Julia, raya en la irreverencia. Hubo diferentes opiniones con respecto a Negrete: mientras unos lo consideraban un delincuente común que actuaba en beneficio propio, para otros era considerado un bandido social, que mataba en defensa propia y repartía los beneficios entre la población. A partir de su muerte, se ha convertido en un héroe justiciero, rebelde social y es considerado por algunos como revolucionario. Incluso, su vida se ha llevado tanto a la televisión como a la pantalla grande, mostrando la infancia terrible que vivió con el asesinato de sus padres y el rapto de su hermana y la muerte en prisión de un hermano que estuvo injustamente encarcelado. Se le compara con Chucho el Roto y Robin Hood: una persona que roba a los ricos para ayudar a los pobres.

En el primer tercio del siglo xx, las mujeres de los sectores sociales bajos se rebelaron a ese rol que les habían asignado. Vivían condiciones de vida como el hacinamiento, la pobreza, la necesidad. También algunas mujeres del sector acomodado comenzaron a sublevarse, lo cual preocupó sobremanera. En consecuencia, se reforzó el modelo de control de la conducta femenina, difundiendo la imagen tradicional a través de los medios; se criminalizó a las disidentes.

Uno de los mecanismos fue el estereotipo divulgado de las criminales. Se les consideraba un sector marginal; dejaban de ser parte de la sociedad. Provenían de clases inferiores. Eran mestizas, dedicadas al servicio doméstico, y no respetaban la vida y los derechos de los demás.

Esta diferencia de género tuvo un efecto social directo en los feminicidios de la época: los crímenes pasionales. Las mujeres fueron asesinadas de acuerdo con tres circunstancias: las mujeres víctimas no habían cometido delito alguno que "justificara" que se les matara; las mujeres que habían hecho algo relacionado con la conducta no permitida por el contexto social; y un tercer grupo que se "justificaba" porque habían querido romper la relación amorosa. Sólo en el caso de que se probara que las mujeres no habían hecho cosa alguna que "justificara" su muerte se condenaba al hombre.

\footnotetext{
${ }^{3}$ Tomado de las notas publicadas por La Prensa el 24 de junio de 1937.
} 
También existía el que mataba por la infidelidad de la pareja, es decir, por celos. El efecto en la sanción penal no tiene comparación con el castigo para las mujeres que cometían crímenes pasionales. Estas sí eran condenadas severamente.

El primer problema que enfrentaba la población era lo sancionable y lo permitido. Para considerar una conducta como delito, tiene que estar tipificada como tal en el Código Penal. Las sanciones tenían que ver con los siguientes aspectos: en primer lugar, en relación con el "Código Penal o legal" (normas de conducta y valores de los legisladores); en segundo, la "sanción judicial" (sentencias de los jueces); y, por último, la "sanción social" (comunidad).

Cada sociedad establece su propia escala de trasgresiones, a las cuales denomina delito. Muchas de ellas son incumplimientos a las normas sociales establecidas. Sin embargo, ciertos sectores son privilegiados. Ocurre, dice la autora, con los homicidios asociados al honor. Mientras para las clases sociales marginales el homicidio se consideraba delito en riña, para las elites no se sancionaba bajo el argumento del honor. La pena por los duelos era más baja que la de riña. La diferenciación de un mismo hecho, homicidio, llevó incluso a definir el Código Nacional Mexicano del Duelo, que fue aplicado sólo a las clases privilegiadas.

El honor era muy especial en el México de esa época. Muestra la autora que hay consenso en diferentes juristas con relación al honor con base en acciones meritorias o virtudes aceptadas en cada momento y lugar (para entonces, el honor masculino se identificaba con estatus social: valentía, fuerza, honradez, lealtad, integridad, destreza, control ejercido sobre las mujeres de la familia y responsabilidad familiar). Así, el hombre debía batirse cuando su virtud era cuestionada; de lo contrario, no sólo admitiría este desmérito, sino que incurriría en otro: la cobardía. ${ }^{4}$ El Código Penal sancionó el duelo, pero lo consideró como un "delito especial", cuya causa era moral; por lo tanto, le impusieron una pena menor que a la riña. Un homicidio por duelo tenía como pena entre 6 y 4 años de prisión; un homicidio en riña, entre 10 y 16.

El texto es un recuento pormenorizado de las ambigüedades y errores en la procuración e impartición de la justicia, motivados por diversos elementos morales e ideológicos del juzgador. Nuestra época no se sustrae de dichas desviaciones. El texto obliga a derivar la necesaria corresponsabilidad disciplinaria que debe tener el juzgador para hacer más eficientes sus decisiones cuando de sanción se trate. No está de más reiterar, como corolario, que se requiere de la psicología jurídica dentro del derecho para humanizar y ayudar a ver más allá de lo que dicta una norma.

\footnotetext{
${ }^{4}$ Speckman, G. E., op. cit., p. 271
} 
Recordemos que el deber ser (derecho) y el ser (psicología) por separado son insuficientes. Sólo en la medida en que se haga un análisis integral del caso que abarque ambos aspectos y analice en forma casuística, se podrá entender la conducta delictiva, ya que nunca podremos generaliza. Tenemos que analizar uno por uno, considerando que cada situación tiene una diferente motivación. La virtud del texto es mostrar, a través de una revisión histórica, la impostergable colaboración del derecho con otras disciplinas, como la psicología jurídica, para un análisis individual, y la sociología jurídica, para un análisis de los aspectos sociales. La criminalidad de un país está en función del estado de descomposición social. 


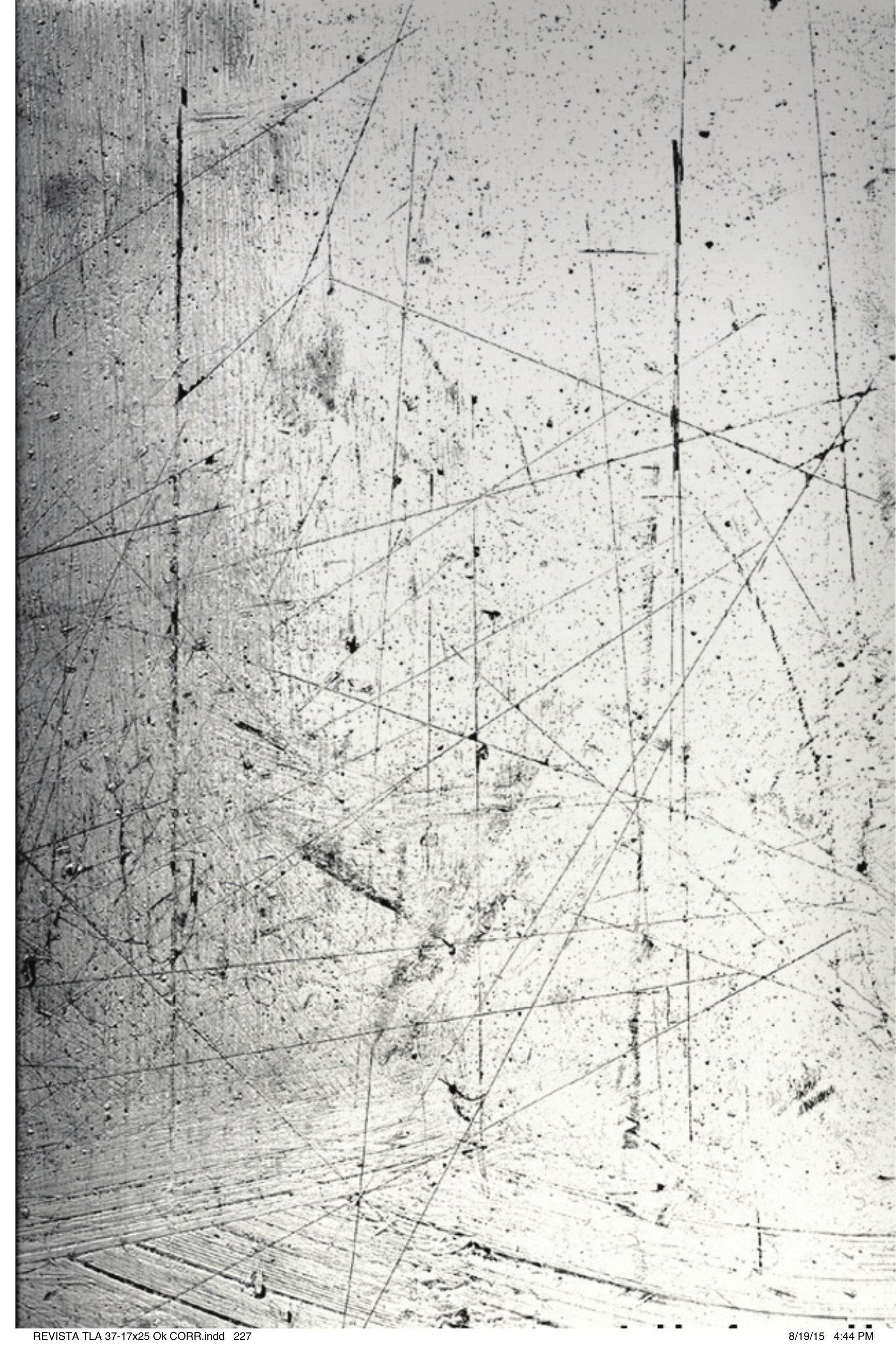

